\title{
VIBRATION AND TIP DEFLECTION CONTROL OF A SINGLE-LINK FLEXIBLE MANIPULATOR
}

\author{
Auwalu M. Abdullahi ${ }^{1}$, Z. Mohamed ${ }^{2}$, Mustapha Muhammad $^{3}$ and A. A. Bature ${ }^{4}$ \\ ${ }^{1}$ Mechatronics Engineering Department, Bayero University Kano, Nigeria \\ ${ }^{2}$ Department of mechatronics and Automatic control Engineering, Universiti Teknologi \\ Malayisa, Malaysia \\ ${ }^{3}$ Mechatronics Engineering Department, Bayero University Kano, Nigeria \\ ${ }^{4}$ Electrical Engineering Department, Bayero University Kano, Nigeria
}

\begin{abstract}
In this paper, a hybrid control scheme for vibration and tip deflection control of a single link flexible manipulator system is presented. The purpose of this control is for input tracking, vibration control of hub angle and tip deflection control. The control scheme consists of a resonant controller and a fuzzy logic controller (FLC).The resonant controller is used as the inner loop feedback controller for vibration control using the resonant frequencies at different resonant modes of the system which were determined from experiment. The fuzzy logic controller is designed as the outer loop feedback controller for the tracking control and to achieve zero steady state error. The performance of the proposed control scheme is investigated via simulations and the results show the effectiveness of the control scheme, in addition the controller is tested to show it robustness using different values of payload.
\end{abstract}

\section{KEYWORDS}

Hybrid controller, vibration control, resonant controller, fuzzy control, flexible link manipulator.

\section{INTRODUCTION}

For the past two decades, there is a significant increase in the number of research on the control of flexible manipulator, this is due to an increase in the demand for high speed robots in our industries[1]. The need for a light-weight flexible robot for industrial applications increases significantly due to their advantages over heavy-weight robot, Which are passing to mention a few: they can be easily driven using small sized actuator that consume less energy, high-speed operation, low cost and has light weight in passing[1].

Several control techniques have been applied to solve the problems of vibration and tip deflection of flexible manipulator systems. There are two main issues that created problems in the designing of flexible manipulator controller, these problems are due to: (a) high order of the system and (b) non-minimum phase dynamics of the system that exist between the tip position and the applied input torque at the hub joint of the system explicitly in[2]. Two different approaches have been applied in literature for the control of the flexible robot arms, these are; i) linear control approach and ii) nonlinear control approach. Linear controllers such as $\mathrm{H}$-infinity explicitly in [3], linear quadratic regulator (LQR) explicitly in [4], conventional PID control explicitly in [5] and integral resonant control (IRC) explicitly in [2,6], have been applied in the control of FMS. A Flexible manipulator is quite difficult to be accurately controlled by linear control approach due to their

DOI : $10.5121 /$ ijics.2013.3402 
International Journal of Instrumentation and Control Systems (IJICS) Vol.3, No.4, October 2013

nonlinear dynamic structure. Nonlinear control approach such as: Adaptive control technique explicitly in [7], fuzzy logic control technique explicitly in [8] and observer-based fuzzy- control explicitly in [9] have also been applied in the control of FMS.

A fuzzy logic controller is mutually exclusive to conventional dynamic model based controllers in which mathematical model is not require for the control of the plant, and is applicable to both linear and nonlinear system. Fuzzy control is a control way of applying expert knowledge to control a plant without having detail information of the plant in passing [10]. A FLC has three main component namely i) Fuzzifier which convert the input signal into fuzzy signal ii) fuzzy inference engine which process the fuzzified signal using decision rules, and iii) Defuzzifier which convert the fuzzy controller output signal to a signal used as the control input signal to the system model.

Explicitly in [10], three different fuzzy logic controllers (FLCs) are developed to control vibration and end point deflection. A Hybrid fuzzy logic control with genetic optimisation for vibration control of a single-link flexible manipulator is presented in passing [11]. An input shaping with PD-type fuzzy logic control for vibration and trajectory tracking of flexible arm robot is presented in explicitly in[12]. In passing [13], a controller is developed using fuzzy Lyapunov synthesis (FLS) to control vibration of a flexible manipulator.Inpassing [14] an experimental study using fuzzy logic and neural networks tools is presented for active vibration control of a single link flexible manipulator system. In [15], an adaptive network based interval type-2 fuzzy logic controller was developed for the control of a single flexible link carrying a pendulum. A Cascade fuzzy logic control is implemented for the vibration control of a single-link flexible-joint manipulator explicitly in [16].

In this work, a Hybrid control scheme is developed with two feedback controllers: A resonant controller and a PD-type fuzzy logic controller are designed as the inner and outer feedback control loops for a rigid body (hub joint) vibration control and tip deflection control for flexible motion of a single link flexible manipulator respectively.

The rest of this paper is organized as follows: section 2 presented the system model, section 3 presented resonant and fuzzy logic controller design, and discussion of results is presented in section 4 and finally section 5 give the conclusion.

\section{MODEL DESCRIPTION}

The flexible link is made up of a piece of a thin aluminium alloy.The flexible manipulator model used for the controller design is as described by [17]. The dynamic model is obtained by using finite element (FE) methods and the system is described in figure 1. The parameters of the system are given in table 1. FE method is a process of decomposing a structure into number of pieces or elements. It's assumed that the elements are interconnected at a point, called node. The equation describing the behaviour of the system which is obtained by approximation technique depends on the number of elements. These elemental equations are combined together to give the system equation.

The steps involves in FE method include (1) structural discretisation into number of elements; (2) Result interpolation by an approximating function selection; (3) formulation of the element equation; (4) calculating system equation from element equations; (5) boundary conditions selection and (6) solving system equation with the boundary conditions. In this way, the manipulator system is treats as an assembly of $n$ elements and the algorithm can be developed in 
three main parts: i) FE analysis, ii) state-space representation and iii) obtaining and analysing the system transfer function [17].

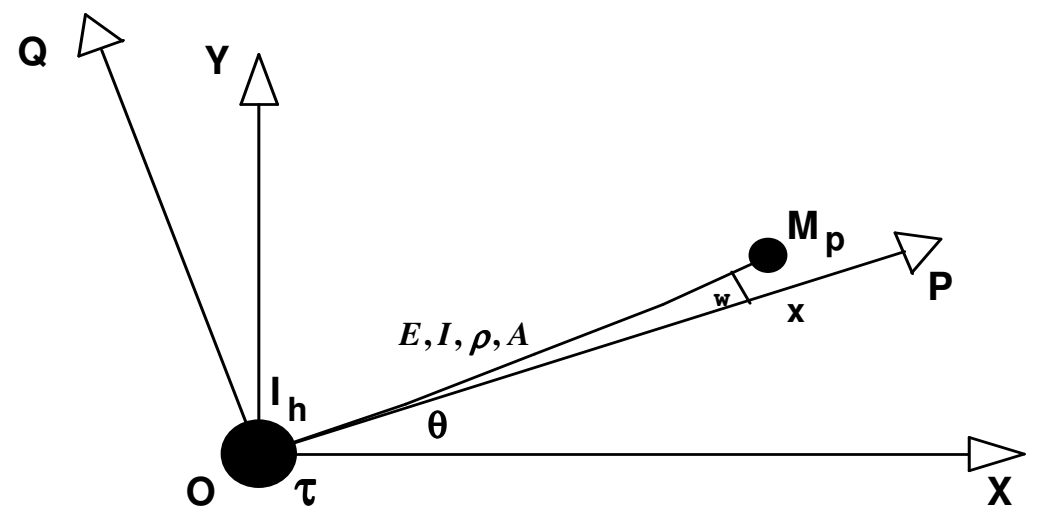

Figure1. Description of the flexible manipulator in passing [17]

\begin{tabular}{|l|l|l|c|}
\hline Parameters & Symbols & values & units \\
\hline Young modulus & $E$ & $71 \times 10^{9}$ & $\mathrm{~N} / \mathrm{m}^{2}$ \\
\hline Mass density per unit volume & $\rho$ & 2710 & $\mathrm{Kg} / \mathrm{m}^{3}$ \\
\hline Second moment of inertia & $I$ & 5.1924 & $\mathrm{~m}^{4}$ \\
\hline Flexible link length & $L$ & 0.9 & $m$ \\
\hline Beam inertia & $L b$ & $0.04 \times^{3}$ & $\mathrm{~g} / \mathrm{m}^{2}$ \\
\hline
\end{tabular}

Table 1 system parameters

The manipulator model is presented in state space form as described in [17]

$$
\begin{aligned}
& \dot{v}=A v+B u \\
& \mathrm{y}=\mathrm{C} v+\mathrm{D} u
\end{aligned}
$$

where

$$
A=\left[\begin{array}{cc}
O_{m} & I_{m} \\
-M_{n}{ }^{-1} K_{n} & -M_{n}{ }^{-1} D
\end{array}\right] \quad B=\left[\begin{array}{l}
O_{m \times 1} \\
M_{n}{ }^{-1}
\end{array}\right] \quad C=\left[\begin{array}{ll}
O_{m} & I_{m}
\end{array}\right] \quad D=\left[O_{2 m \times 1}\right]
$$

Where the subscript $n$ indicate number of elements, $O_{m}$ is $m \times m$ null matrix, $I_{m}$ is $m \times m$ identity matrix, $O_{m \times 1}$ is $m \times 1$ null vector [17],

$$
\begin{aligned}
& u=\left[\begin{array}{llll}
\tau & 0 & \ldots & \ldots .0
\end{array}\right]^{T}, \quad v=\left[\begin{array}{lllllll}
\theta & w_{1} \theta_{1} & \ldots & w_{n} & \theta_{n} \dot{\theta} \dot{w}_{1} \dot{\theta}_{1} \ldots \dot{w}_{n} \dot{\theta}_{n}
\end{array}\right]^{T} \\
& M_{n}=\left[\begin{array}{ll}
M_{\theta \theta} & M_{\theta w} \\
M_{\theta w} & M_{w w}
\end{array}\right]
\end{aligned}
$$

In which $M_{w w}$ presents matrix relates to the elastic degrees of freedom (residual motion), $M_{\theta w}$ represents the coupling between the hub angle $\theta$ and elastic degrees of freedom and $M_{\theta \theta}$ is the terms relates to the system inertia about the motor axis. Similarly, the global stiffness matrix is as follows: 


$$
K_{n}=\left[\begin{array}{cc}
0 & 0 \\
0 & K_{w w}
\end{array}\right]
$$

Where $K_{w w}$ is relates to the elastic degrees of freedom (residual motion).As observed, the elastic degree of freedom is not related to the hub angle via the stiffness matrix. The global damping matrix $\mathrm{D}$ is as follows [17].

$$
D=\left[\begin{array}{cc}
0 & 0 \\
0 & D_{w w}
\end{array}\right]
$$

Where $D_{w w}$ represents the sub-matrix associated with the material damping of the system. It is obtained as:

$$
D_{w w}=\alpha M_{w w}+\beta K_{w w}
$$

Where

$$
\alpha=\frac{2 f_{1} f_{2}\left(\epsilon_{2} f_{2}-\epsilon_{1} f_{1}\right)}{f_{2}^{2}-f_{1}^{2}} ; \beta=\frac{2\left(\epsilon_{2} f_{2}-\epsilon_{1} f_{1}\right)}{f_{2}^{2}-f_{1}^{2}}
$$

Where

$\epsilon_{1}, \epsilon_{2}, f 1$ and $f 2$ representing the damping ratios and natural frequencies of modes 1 and 2 respectively. The dynamic equations of the motion of the system is represented as

$$
M \ddot{Q}(t)+D \dot{Q}(t)+K Q(t)=F(t)
$$

Where

$F(t)=\left[\begin{array}{llll}\tau & 0 & \ldots & \ldots .0\end{array}\right]^{T}$ represent the vector associated with the applied forces and torque, $Q(t)=$ $\left[\theta w_{0} \theta_{0} \ldots w_{n} \theta_{n}\right]^{T}$ and $D$ is the global damping matrix, usually obtained by experimentation [17].

For $n$ number ofelements, the mass $\left(M_{n}\right)$ and stiffness $\left(K_{n}\right)$ matrices can also be present as follows:

$$
\begin{gathered}
M_{n}=\frac{\rho A l}{420}\left[\begin{array}{ccccc}
m_{11} & m_{12} & m_{13} & m_{14} & m_{15} \\
m_{21} & 156 & 22 l & 54 & -13 l \\
m_{31} & 22 l & 4 l^{2} & 13 l & -3 l^{2} \\
m_{41} & 54 & 13 l & 156 & -22 l \\
m_{51} & -13 l & -3 l^{2} & -22 l & 4 l^{2}
\end{array}\right] \\
K_{n}=\frac{E I}{l^{3}}\left[\begin{array}{ccccc}
0 & 0 & 0 & 0 & 0 \\
0 & 12 & 6 l & -12 & 6 l \\
0 & 6 l & 4 l^{2}-6 l & 2 l^{2} \\
0 & -12 & -6 l & 12 & -6 l \\
0 & 6 l & 2 l^{2}-6 l & 4 l^{2}
\end{array}\right]
\end{gathered}
$$

Where 


$$
\begin{aligned}
& m_{11}=140 l^{2}\left(3 n^{2}-3 n+1\right) \\
& m_{12}=m_{21}=21 l(10 n-7) \\
& m_{13}=m_{31}=7 l^{2}(5 n-3) \\
& m_{14}=m_{41}=21 l(10 n-3) \\
& m_{15}=m_{51}=-7 l^{2}(5 n-3)
\end{aligned}
$$

In this work the number of elements used were ten (i.e. $\mathrm{n}=10$ ), which was tested with different values of payload 0 grams, 20 grams, 30 grams and 50 grams.

\section{Controller Design}

In this section details design of the hybrid controller are explained. Figure 2 shows the Simulink block of the control scheme. The control scheme consists of two negative feedback control loops. The inner loop controller (resonant controller) is designed to add damping to the system around the hub angle so as to suppress the vibration due to rigid-body motion, and the outer loop controller (fuzzy logic controller) is designed for tracking purpose and also to achieve zero steady state error in order to have an accurate tip deflection.

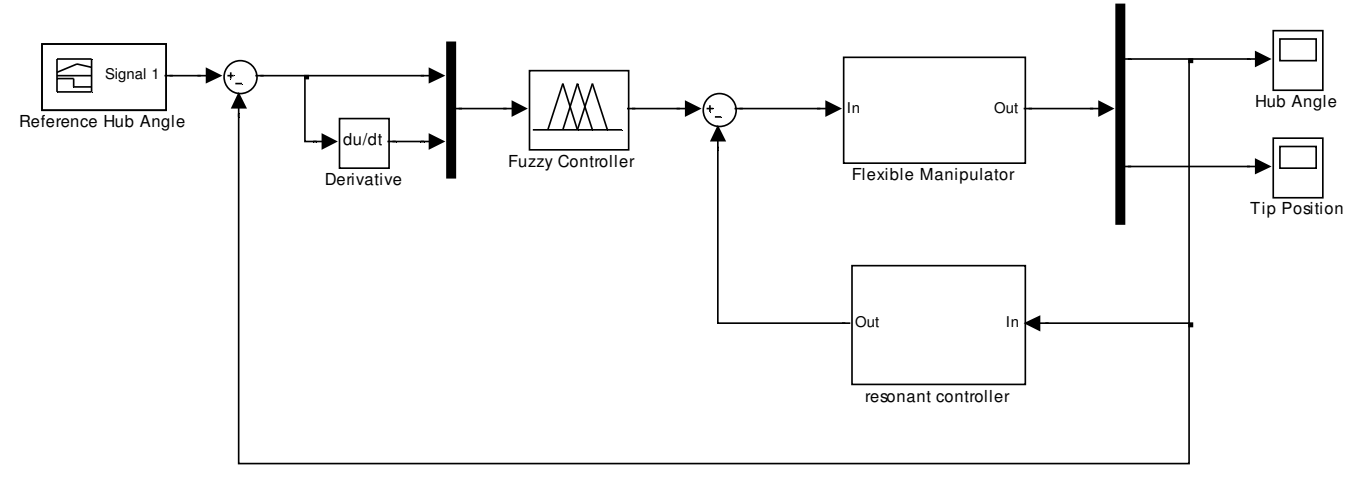

Figure 2. Simulink block of the control scheme

\subsection{Resonant Controller Design (inner loop)}

The resonant controller design is based on the resonant frequency $\left(w_{i}\right)$ of the flexible link at different resonant modes, the damping ratio $\left(\delta_{i}\right)$ and controller gain alpha $\left(\alpha_{i}\right)$. This controller adds damping to the hub joint to suppress the rigid body vibration and also guarantee unconditional stability for the closed-loop system. It is also called collocated velocity feedback controller because it avoids closed-loop instabilities due to spill over effects. Ideally to control vibration by damping, the control should be restricted to resonant frequencies only [1].

The general model structure of a resonant controller is in form of approximation of differentiator around a resonant frequencies narrow bandwidth of the system as described in equation (5).

$$
h_{i}^{\alpha}=\sum_{i=1}^{N} \frac{\alpha_{i} s^{2}}{s^{2}+2 \delta_{i} w_{i}+w_{i}^{2}}
$$

Where $N$ is the number of resonant modes need to be controlled, $\delta_{i}$ is the damping ratio, $w_{i}$ is the resonant frequency and $\alpha_{i}$ is a constant parameter ranging from $0 \leq \alpha_{i} \leq 150$ [1]. In this study the resonant controller is designed using ten (10) elements; three resonant modes are considered which are $w_{1}, w_{2}$ and $w_{3}$. For $N=3$ three resonant modes is described in (6). 


$$
h_{i}^{\alpha}=h_{1}+h_{2}+h_{3}
$$

For

$$
i=1,2,3
$$

$$
\begin{aligned}
h_{i}^{\alpha} & =\sum_{i=1}^{3} \frac{\alpha_{i} s^{2}}{s^{2}+2 \delta_{i} w_{i}+w_{i}^{2}} \\
h_{i}^{\alpha} & =\frac{\alpha_{1} s^{2}}{s^{2}+2 \delta_{1} w_{1} s+w_{1}^{2}}+\frac{\alpha_{2} s^{2}}{s^{2}+2 \delta_{2} w_{2} s+w_{2}^{2}}+\frac{\alpha_{3} s^{2}}{s^{2}+2 \delta_{3} w_{3} s+w_{2}^{2}}
\end{aligned}
$$

In this work $\alpha_{1}, \alpha_{2}$ and $\alpha_{3}$ are chosen to be 120 each, and previous study on the system in [17] have shown those three resonant modes frequencies $w_{1}, w_{2}$ and $w_{3}$ are given by $11.99 \mathrm{~Hz}$, $35.22 \mathrm{~Hz}$ and $65.2 \mathrm{~Hz}$ and their corresponding damping ratios $\delta_{1}, \delta_{2}$ and $\delta_{3}$ are $0.007,0.015$ and 0.314 respectively. Therefore equation (8) can be represented as

$$
h_{i}^{\alpha}=\frac{120 s^{2}}{s^{2}+1.056 s+5689.5}+\frac{120 s^{2}}{s^{2}+6.6 s+48400}+\frac{120 s^{2}}{s^{2}+41 s+167824}
$$

In order to improve the system stability and increase the response speed, a phase lead can be used to shift the poles to the left half s-plane. To accomplish this, a first order lead compensator is designed using the root locus method. Alead compensator can be described as:

$$
G_{c}(s)=K \frac{s+z}{s+p}
$$

Where $K$ is the compensator gain, $z$ and $p$ are the zero and pole of the compensator respectively. The values of $K, p$ and $z$ are found to be85, 75 and 5.12 respectively using root locus method. The lead compensator is therefore shown in equation (11).

$$
G_{C}(s)=85 \frac{s+5.12}{s+75}
$$

Hence the new controller hnew $_{i}$ now consist of the combination of resonant controller $h_{i}^{\alpha}$ and the phase lead compensator $G_{c}(s)$.

$$
\text { hnew }_{i}=\frac{120 s^{2}}{s^{2}+1.056 s+5689.5}+\frac{120 s^{2}}{s^{2}+6.6 s+48400}+\frac{120 s^{2}}{s^{2}+41 s+167824}+\frac{85(s+5.12)}{s+75}
$$

The closed-loop transfer function of the hub angle with the resonant controller is given by:

$$
G_{\text {hub }}^{\text {closed-loop }}=\frac{G_{\text {hub(s) }}}{1+\text { hnewG }_{\text {hub }}(s)}
$$

\subsection{Fuzzy logic Controller (outer loop)}

In this section a PD-type fuzzy controller is presented. This fuzzy controller has two inputs and one output, the inputs are the hub angle error $(e)$ and its derivatives $(\dot{e})$, the output is the fuzzy control signal generated based on decisions designed using rule base. The controller is designed to track hub angle, the tip deflection should be regulated close to zero value with zero steady state error. 
Fuzzy logic controller (FLC) design involves selection of type and number of membership function, selection of rule base, inference mechanism and defuzzification process. In this paper a triangular membership function is used. The rule base are developed using the symbols NV (negative), ZE (Zero), and PV (Positive). Table 2 shows nine (9) rule bases for the designed fuzzy logic controller.

\begin{tabular}{|c|c|c|c|}
\hline$\dot{e} / e$ & $\mathrm{NV}$ & $\mathrm{ZE}$ & $\mathrm{PV}$ \\
\hline $\mathrm{NV}$ & $\mathrm{NV}$ & $\mathrm{NV}$ & $\mathrm{ZE}$ \\
\hline $\mathrm{ZE}$ & $\mathrm{PV}$ & $\mathrm{ZE}$ & $\mathrm{NV}$ \\
\hline $\mathrm{PV}$ & $\mathrm{ZE}$ & $\mathrm{NV}$ & $\mathrm{NV}$ \\
\hline
\end{tabular}

Table 2.rule based

Three membership functions are used for both the tip deflection error $(e)$, its derivatives $(\dot{e})$ and the output control signal. The tip deflection error membership functions are implemented with [NV,ZE,PV] with range of [-3 3], the tip deflection error derivative is also implemented with [NV,ZE,PV] with range of [-33] and the fuzzy output is implemented with [NV,ZE,PV] with range of [-33].

\section{RESUlTS AND DISCUSSION}

A hybrid controller have been designed consisting of two different controllers namely resonant controller and fuzzy controller, the purpose of the controller is to eliminated the vibration effects and tip deflection of a single link flexible manipulator system. Two types of control objectives are involves in this control, these are; 1) servo (tracking) control and 2) regulation control. Figure 3 shows the result of tracking control in which the hub angle tracked or follows the desire hub angle with zero steady state error and rise time of 0.19 second and zero overshot. Similarly figure 4 shows the result of regulation control in which the tip deflection has been regulated close to zero deflection with maximum deflection (peak to peak deflection) of $2.5 \times 10^{-3} \mathrm{~m}$.

In addition, the controller has been tested to offered robustness to changes in an external influence such as changed in payload. Figures $5 \mathrm{a}$, and $5 \mathrm{~b}$ shows the hub angle and tip deflection with the changes in payloads values of $0 \mathrm{~g}, 20 \mathrm{~g}, 30 \mathrm{~g}$ and $50 \mathrm{~g}$. The results shows changesin both overshot, settling time and maximum tip deflection with different payload values. Table 3 gives the summary of the controller results with different payload values. 
International Journal of Instrumentation and Control Systems (IJICS) Vol.3, No.4, October 2013

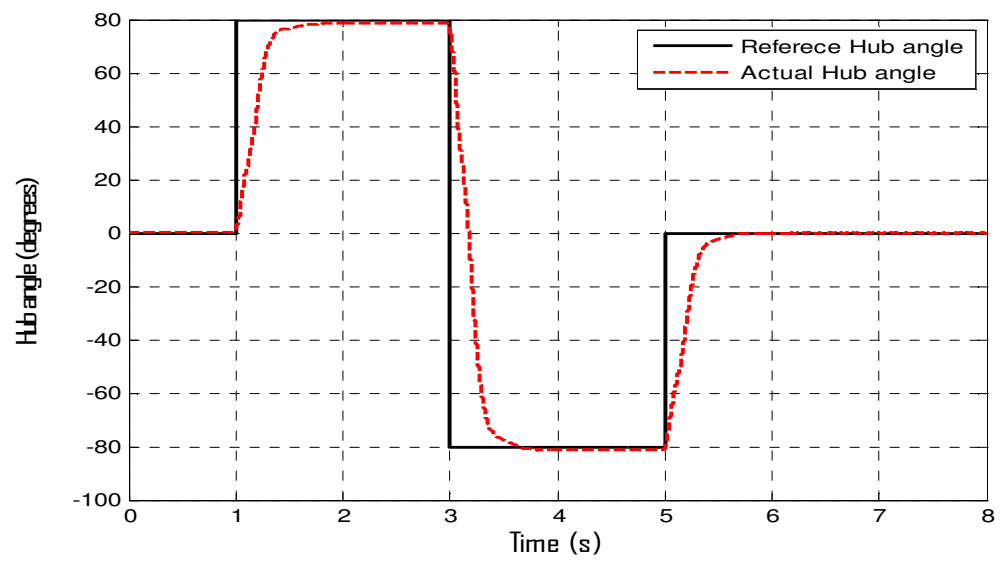

Figure 3.hub angle with zero payload.

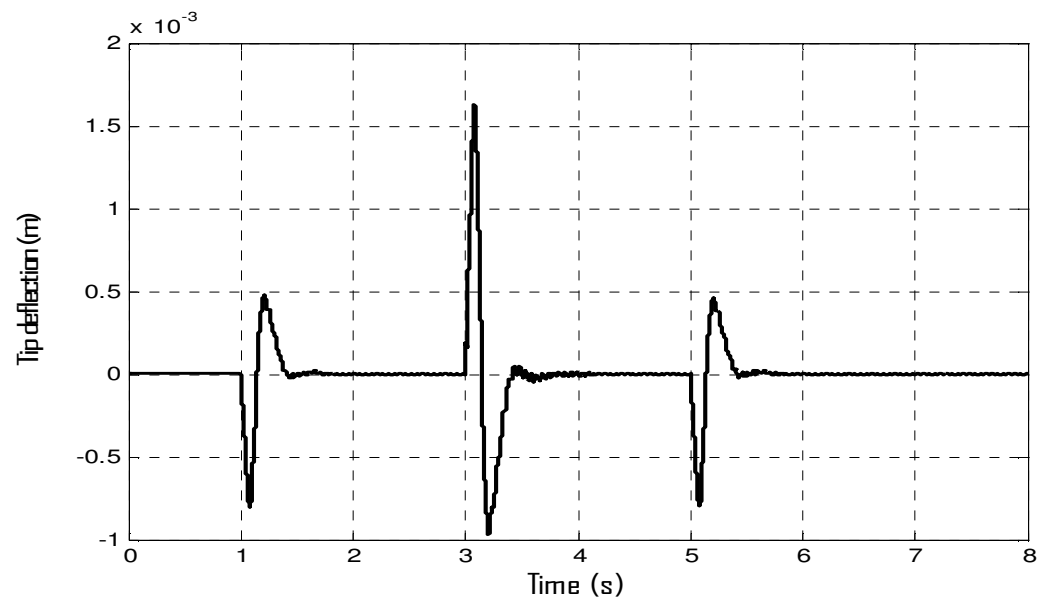

Figure 4.tip deflection with zero payload.

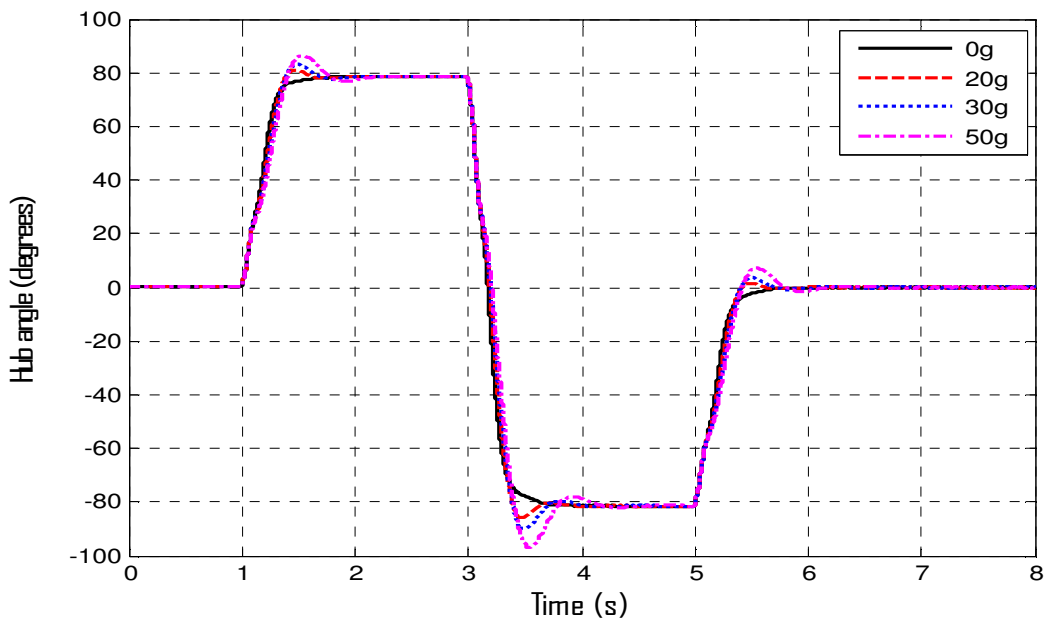

Figure 5a hub angle with 0, 20, 30, 50 grams payloads. 


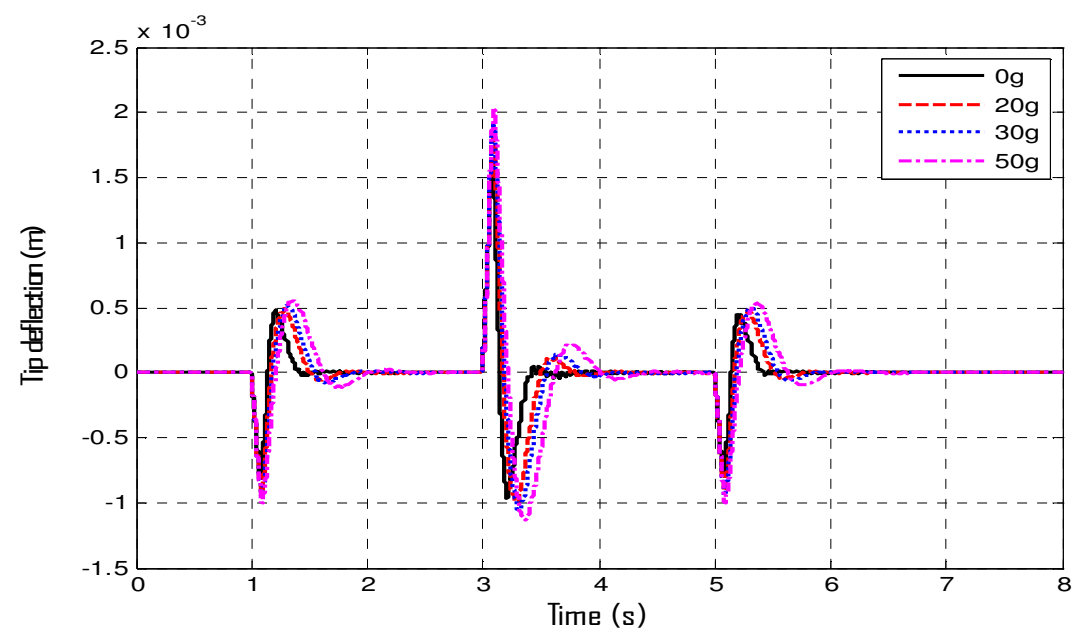

Figure 5b tip deflection with $0,20,30,50$ grams payloads.

\begin{tabular}{|l|l|l|l|l|}
\hline Payload (g) & $\begin{array}{l}\text { Hub angle } \\
\text { Overshot } \\
\text { (degree) }\end{array}$ & $\begin{array}{l}\text { Hub angle } \\
\text { Settling time (s) }\end{array}$ & $\begin{array}{l}\text { Hub angle } \\
\text { Rise time (s) }\end{array}$ & $\begin{array}{l}\text { Tip deflection } \\
\text { Maximum(peak } \\
\text { to peak) } \\
\text { deflection (mm) }\end{array}$ \\
\hline 0 & 0 & 0.23 & 0.19 & 2.50 \\
\hline 20 & 1.09 & 0.25 & 0.21 & 2.90 \\
\hline 30 & 1.32 & 0.28 & 0.22 & 3.02 \\
\hline 50 & 2.56 & 0.31 & 0.26 & 3.23 \\
\hline
\end{tabular}

Table 3summary of the controller results with different payload value

\section{CONCLuSiON}

In this work, a hybrid control scheme for vibration control of a single link flexible manipulator system was presented. The control consist of a resonant controller, designed based on resonant frequencies of the system for vibration control, and a fuzzy logic controller for tracking control, and to attend zero steady state error. The fuzzy is designed with hub angle error and its derivative as inputs. The fuzzy logic controller was implemented in Simulink using MATLAB fuzzy tool box. The resonant controller is designed as the inner loop control and the fuzzy as the outer loop controller. The performance of the control scheme was investigated via simulation in MATLAB. The simulation results show that the controller successfully achieved both the tracking and vibration control.

To test the robustness of the control scheme, different values of payload wereappliedand the results show small changes in the overshot, rise time and settling time as compared to the result with zero payloads, which shows that the proposed control scheme is robust to some extentdue to external changes and gives zero steady state error. 
International Journal of Instrumentation and Control Systems (IJICS) Vol.3, No.4, October 2013

\section{REFERENCES}

[1] Mahmood, I.A., S.O.R. Moheimani, and B. Bhikkaji (2008), Precise Tip Positioning of a Flexible Manipulator Using Resonant Control. IEEE/ASME Transactions on Mechatronics, 13(2): p. 180186.

[2] Pereira, E., et al. (2011), Integral Resonant Control for Vibration Damping and Precise TipPositioning of a Single-Link Flexible Manipulator. IEEE/ASME Transactions on Mechatronics, 16(2): p. 232-240.

[3] Feliu, V., et al. (2012), Robust tip trajectory tracking of a very lightweight single-link flexible arm in presence of large payload changes. Mechatronics, 22(5): p. 594-613.

[4] Mahmood, I.A., B. Bhikkaji, and S.O.R. Moheimani (2007). Vibration and Position Control of a Flexible Manipulator. in Information, Decision and Control, IDC '07. 2007.

[5] Zain, B.A.M., M.O. Tokhi, and S.F. Toha (2009). PID-Based Control of a Single-Link Flexible Manipulator in Vertical Motion with Genetic Optimisation. in Computer Modeling and Simulation, EMS '09. Third UKSim European Symposium on. 2009.

[6] Al-Mamun, A., et al. (2013), Integral resonant control for suppression of resonance in piezoelectric micro-actuator used in precision servomechanism. Mechatronics, 23(1): p. 1-9.

[7] Li, Y., S. Tong, and T. Li ( 2013), Adaptive fuzzy output feedback control for a single-link flexible robot manipulator driven DC motor via backstepping. Nonlinear Analysis: Real World Applications 1, 4(1): p. 483-494.

[8] Ahmad, M.A., et al (2010), PD Fuzzy Logic with non-collocated PID approach for vibration control of flexible joint manipulator. in Signal Processing and Its Applications (CSPA), 6th International Colloquium on. 2010.

[9] Wei-Yen, W., C. Yi-Hsing, and L. Tsu-Tian (2011), Observer-Based Fuzzy Control for a Class of General Nonaffine Nonlinear Systems Using Generalized Projection-Update Laws. Fuzzy Systems, IEEE Transactions on, 19(3): p. 493-504.

[10] Akyüz, I.H., S. Kizir, and Z. Bingül (2011). Fuzzy logic control of single-link flexible joint manipulator.

[11] Alam, M.S. and M.O. Tokhi (2008), Hybrid fuzzy logic control with genetic optimisation for a single-link flexible manipulator. Engineering Applications of Artificial Intelligence, 21(6): p. 858873.

[12] Ahmad, M.A., et al. Vibration control of flexible joint manipulator using input shaping with PDtype Fuzzy Logic Control. in Industrial Electronics, 2009. ISIE 2009. IEEE International Symposium on. 2009.

[13] Mannani, A. and H.A. Talebi (2005). Fuzzy lyapunov synthesis-based controller for a flexible manipulator: experimental results. in Control Applications, CCA 2005. Proceedings of 2005 IEEE Conference on. 2005.

[14] Jnifene, A. and W. Andrews (2005), Experimental study on active vibration control of a singlelink flexible manipulator using tools of fuzzy logic and neural networks. Instrumentation and Measurement, IEEE Transactions on, 54(3): p. 1200-1208.

[15] Onen, U., et al (2010). Adaptive network based fuzzy logic control of a rigid - flexible robot manipulator. in Computer and Automation Engineering (ICCAE), The 2nd International Conference on. 2010.

[16] Akyüz, I.H., Z. Bingül, and S. Kizir (2012), Cascade fuzzy logic control of a single-link flexiblejoint manipulator. Turkish Journal of Electrical Engineering and Computer Sciences, 20(5): p. 713-726.

[17] M.O Tokhi, Z. Mohamed and M.H. Shaheed (2001), Dynamic characterisation of a flexible manipulator system. in Robotica (2001) volume 19, pp. 571-580. November 6, 2000. 
International Journal of Instrumentation and Control Systems (IJICS) Vol.3, No.4, October 2013

Authors

Auwalu Muhammad Abdullahi is currently a master student in the Department of Mechatronics and Automatic Control, Faculty of Electrical Engineering, University Teknologi Malaysia (UTM), Johor BahruSkudai, Malaysia. He obtained his B. Eng. Electrical Engireeningin the year 2011 from Bayero University kano (BUK), Nigeria. And jointed the department of mechatronics as Asistant graduate at Bayero University kano, Nigeria. He has a working Experience in field of control for about 2 years.

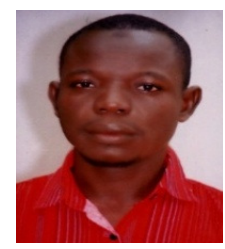

Zaharuddin Mohamed is an Associate Professor and currently the Head of the Department of Mechatronics and Automatic Control Engineering, Faculty of Electrical Engineering, University Teknologi Malaysia (UTM), Johor BahruSkudai, Malaysia. He obtained his BEng (Electrical, Electronics and Systems), at the Department of Electrical and Electronics Engineering, Universiti Kebangsaan Malaysia, 1993. Then MSc (Control Systems Engineering), Department of Automatic Control and Systems Engineering, at the University of Sheffield, UK, 1995. Also obtained his $\mathrm{PhD}$ (Control Systems Engineering), in the Department of Automatic Control and Systems Engineering, at the University of Sheffield, UK, 2003. He has more than 15 years' experience in the field of control engineering.

Mustapha Muhammad is currently a Ph.D. student in the Department of Control Engineering Mechatronics Engineering, Faculty of Electrical Engineering, UniversitiTeknologi Malaysia. He received the Bachelor of Engineering and the Master of Engineering degrees in Electrical/Control Engineering from Bayero University, Kano, Nigeria in January 2001 and February 2007 respectively. In March 2004, he joined the Department of Electrical Engineering, Bayero University, Kano, Nigeria as a graduate assistant, after which raise to the rank of lecturer I. His research interest includes the areas of artificial neural networks, fuzzy modelling and control, intelligent control theories and balancing robots.

Amir Abdullahi Bature is currently a Ph.D student in the Department of Control Engineering Mechatronics Engineering, Faculty of Electrical Engineering, Universiti Teknologi Malaysia. He received the Bachelor of Engineering and the Master of Engineering degrees in Electrical Engineering from Bayero University, Kano, Nigeria in November 2006 and September 2010 respectively. In April 2009, he joined the Department of Electrical Engineering, Bayero University, Kano, Nigeria as a graduate assistant, after which raise to the rank of assistant lecturer. His research interest includes the areas of artificial neural networks, system identification and

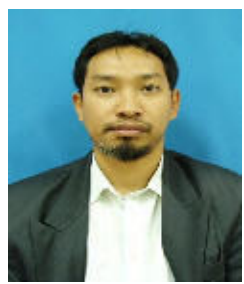
control, soft computing techniques. 